\title{
Simplified Material Solution for Orthotropic Symmetrical GFRP Laminates for Structural Facades
}

\author{
Yuchao Zhao $\mathbb{D}^{1},{ }^{1}$ Xu Jiang $\mathbb{D}^{2}{ }^{2}$ Qilin Zhang $\left(\mathbb{D},{ }^{1}\right.$ and Xuhong Qiang $\mathbb{D D}^{1}$ \\ ${ }^{1}$ Department of Structural Engineering, Tongji University, Shanghai 200092, China \\ ${ }^{2}$ Department of Bridge Engineering, Tongji University, Shanghai 200092, China \\ Correspondence should be addressed to Qilin Zhang; zhangqilin@tongji.edu.cn
}

Received 18 April 2019; Revised 6 July 2019; Accepted 21 July 2019; Published 1 October 2019

Academic Editor: Constantin Chalioris

Copyright (C) 2019 Yuchao Zhao et al. This is an open access article distributed under the Creative Commons Attribution License, which permits unrestricted use, distribution, and reproduction in any medium, provided the original work is properly cited.

GFRP (glass-fiber-reinforced polymer), as a composite material, possesses many favorable properties including high strength and low weight and is amenable to unique processing methods; therefore, it is a potential free-form surface material. However, the complex design theory owing to anisotropy limits its application. Thus, a simplified material solution becomes significant. In this study, the strength and stiffness of orthotropic symmetrical GFRP laminates are derived theoretically, and a simplified material solution is proposed to simplify the anisotropy as isotropy. Then, using the numerical simulation of an actual orthotropic symmetrical GFRP laminate free-form facade structure, the effectiveness of the simplified material solution is analyzed and evaluated. This solution can provide guidance for similar GFRP facades and further promote the application of GFRP in engineering.

\section{Introduction}

Recent times have seen the construction of a number of special-shaped buildings around the world. However, the realization of these complex architectural shapes poses great challenges for engineers. Traditional facade materials like glass, metal, and concrete cannot be used to construct freeform facades without significant construction time and costs considering the current technical conditions. GFRP (glassfiber-reinforced polymer), as composite material, possesses many favorable properties including high strength and low weight and is amenable to unique processing methods. It seems to be a potential solution for free-form facades.

GFRP represents a series of composite materials that employs a polymer as the matrix and glass fiber as the reinforcing material. Although it is a relatively new material compared to traditional materials such as steel and concrete, it has been applied in civil engineering ever since its invention. However, its applications were limited until recent years. Of late, GFRP has been used to fabricate bridge decks, structural reinforcements, bars, and decoration materials.
As reinforcement material, Kurt [1] tested the properties of plastic pipes filled with concrete and used to strengthen concrete columns in 1977. Although the plastic pipes are not strictly fiber-reinforced polymers (FRP, GFRP is a typical FRP), this could be regarded as a study that pioneered composite material reinforcement. Since then, researchers from Japan and the USA worked continuously on FRP applications, and multiple achievements were made in terms of reinforcement [2]. In 1988, carbon-fiber-reinforced polymer (CFRP) stranded wires were applied as prestressed reinforcements on the new Shinmiya bridge in Japan $[3,4]$. In 2003, B. Täljsten studied the strengthening concrete beams for shear with CFRP sheets and briefly concluded how to design it [5]. Zadeh and Nanni presented methodologies for the design of concrete columns in their articles and highlight some important aspects affecting computations [6,7]. Based on a large database collected from the literature, Jumaa and Yousif proposed three prediction models to estimate the shear capacity of FRP-RC members using artificial neural networks, gene expression programming, and nonlinear regression analysis [8]. Currently, composite bridge construction is the 
major application of FRP structures and also the most technology-mature full-FRP structure form now available. Composite bridges were first built in the 1980s, where FRP was employed as deck and beam materials. In 1983, an FRP honeycomb box girder highway bridge was built in Miyun, Beijing [9], which was the first FRP highway bridge. FRP pedestrian bridges are highly praised due to the lightweight and the ease in fabrication and installation. Many innovative FRP pedestrian bridges have been constructed in Asia, Europe, and North America [10, 11]. FRP is also applied as link slabs of bridge decks. In 2012, Saber and Ashok investigated the use of glass-fiber-reinforced polymers grid for reinforcement in link slabs for jointless bridge decks [12].

FRP was first employed as a building facade material in the 1950s, when composite materials were just beginning to find civilian applications. Although several creative FRP house prototypes were developed, only a few of them were applied successfully. In 1956, the Maison en Plastique, which was regarded as the first ever structure with load-bearing FRP members, was set up in Paris [13]. The structure was designed for the Salon des Arts; inspired by the snail, the house could be enlarged using addition modules around the circular core. In the same year, the famous Monsanto House of the Future [14], whose C-shaped surface was made of GFRP, was constructed in Disneyland, Orlando. Futuro, 1968 [15], possessed a distinctive GFRP-saucer shape and was the prototype of many subsequent GFRP structures. In 2005, the Yitzhak Rabin Center was built in Tel Aviv, Israël. To commemorate Yitzhak Rabin's contribution to peace, the roof of the great hall and library are designed to resemble dove wings using composite materials. Similarly, the Mobile Art Chanel Contemporary Art Container was designed by Zaha Hadid Architecture and started its travel in 2008 [16]. The facade of the free-form "mobile" structure is made of FRP; the ease of processing and low weight characteristics are extremely valuable in the fabrication of this structure. Low cost, no heavy machinery requirements, and convenience of assembly, disassembly, and transport make FRP free-form facade structures desirable.

The inherent anisotropy of FRP is not very difficult for researchers. However, it is too complicated for applications in actual engineering. It results in complicated design theories that, in turn, require extensive calculations, thus directly limiting its applications. In recent years, some simplified calculation methods were proposed for composite materials. In 2014, a simplified reliability-based determination procedure on the strengthening ratio of a deteriorated concrete girder with CFRP strips was proposed [17]. In 2018, Ozbakkaloglu et al. proposed a simple yet powerful design-oriented model to predict the axial stress-strain behavior of FRP-confined concrete in circular sections [18-20]. In 2019, Zhang et al. proposed a simplified theoretical solution for the evaluation of the equivalent bending stiffness of a unique hybrid FRPaluminum spatial deck-truss structure [21]. However, simplified design methods for pure FRP members in engineering are still rare.

As facade material or load-bearing single shell members, the utilization value of orthotropic symmetrical GFRP laminates is the highest in terms of cost, process, and performance. The orthotropic symmetrical GFRP laminates in this paper are reinforced equally in two mutually perpendicular directions, such as $0^{\circ}$ and $90^{\circ}$. This study proposes a simplified material solution to transform the anisotropy of orthotropic GFRP laminates into isotropy.

This study involves the theoretical derivation of the strength and stiffness of orthotropic symmetrical GFRP laminates and obtains the off-axis strength and stiffness. Bending experiments and corresponding finite element method analysis are carried out, and their results are compared to verify the consistency. Numerical simulation of an actual GFRP free-form facade is performed, in which the GFRP material and simplified material properties are employed, respectively, to examine the accuracy and effectiveness of the simplified solution. The simplified material solution is ultimately applied to the design of the actual GFRP free-form facade, and the construction of the free-form facade was completed during early December 2017.

\section{Simplification Necessity}

Theoretical research on the anisotropic properties of composite materials has always been the focus for composite material research. Although some theories are in good agreement with the actual performance of composites materials under specific conditions, their value in practical application is limited and experiments are always required to further examine FRP products. Generally, engineers are cautious when assuming composite material property values. Most current FRP-related codes and standards in civil engineering mainly deal with structural reinforcement, and some of them involve FRP pultruded profiles [22-26]. These codes provide some regulations and criteria for FRP indexes, but there are no recommended or convenient calculation methods to compute these indexes.

Unidirectional reinforced GFRP can only bear load in the longitudinal direction as its properties in the transverse direction are too weak, and when applied to unidirectional members, it is almost identical to traditional isotropic materials. For multidirectional load-bearing members, orthotropic symmetrical GFRP laminates are mostly applied due to their relatively low cost, ease of processing, and relatively stable properties. The anisotropy of orthotropic symmetrical GFRP laminate is significant, which distinguishes it from conventional building materials. Generally, the stiffness of FRP is calculated based on the classical laminate theory, and failure criteria include the maximum stress criterion, maximum strain criterion, Tsai-Hill criterion, and Tsai-Wu criterion. The Tsai-Hill and Tsai-Wu criteria $[27,28]$ are widely applied for anisotropic materials, and codes such as Eurocode [24] use the Tsai-Hill criterion to verify ply level failure, and the maximum strain criterion for preliminary design to verify laminate-level failure. However, the calculation of these stresses and strains is uncertain in the codes, and it is suggested that experiments should be conducted. Most designers and engineers are unfamiliar with anisotropic materials, not to mention the calculations regarding composite materials like GFRP. This 
is a direct factor that limits the application of GFRP in civil engineering.

In addition, even if designers are familiar with GFRP, it is still difficult to analyze orthotropic symmetrical GFRP laminate structures directly using composite material properties, especially when the calculation involves a large number of panels of various shapes as in a GFRP free-form facade. As a multilayer material, a single GFRP panel can be considered as a composite member, so that the calculation requirement is equivalent to that of a small structure. Therefore, the calculations pertaining to an entire structure is equivalent to several structures at least. For buildings or structures, macroscopic indexes like the maximum deformation are the most relevant factors, and the working environments of buildings are complicated so that a certain error in the calculation is always acceptable. Therefore, the practical significance of laminate-level calculation is relatively limited, and it is necessary to propose a simplified material solution.

The simplified material solution should satisfy three requirements:

(a) The calculated results pertaining to members or structures that apply simplified material properties are in good agreement with the original properties

(b) The simplified material properties can be obtained conveniently through specific experiments

(c) The simplified material solution should guarantee the safety of the structure, and so it should be a relatively conservative solution

Therefore, the target is to simplify orthotropic symmetrical laminates into the isotropic material, thus avoiding anisotropic properties, specifying appropriate stiffness and strength parameters for design reference, reducing design difficulty, and further promoting the application of GFRP in civil engineering.

\section{Theoretical Derivation}

3.1. Stiffness. According to the classical laminate theory, the load-strain matrix of the laminate is shown in the following equation:

$$
\left\{\begin{array}{l}
\mathbf{N} \\
\mathbf{M}
\end{array}\right\}=\left[\begin{array}{ll}
\mathrm{A} & \mathrm{B} \\
\mathrm{B} & \mathrm{D}
\end{array}\right]\left\{\begin{array}{l}
\boldsymbol{\varepsilon}^{0} \\
\mathbf{k}
\end{array}\right\},
$$

where $\mathbf{N}$ is the in-plane force vector, $\mathbf{M}$ is the in-plane moment (torque) vector, $\mathbf{A}$ is the in-plane stiffness matrix, $\mathbf{B}$ is the coupling stiffness matrix, $\mathbf{D}$ is the bending stiffness matrix, $\boldsymbol{\varepsilon}^{0}$ is the midplane strain vector, and $\mathbf{k}$ is the midplane curvature vector.

An orthotropic symmetrical laminate is a special laminate having coupling stiffness matrix $\mathbf{B}$ equal to zero, and the 16 and 26 matrix components of $\mathbf{A}$ and $\mathbf{D}$ are also zero. Thus, no tensile-shear coupling and tensile-bending coupling exist. Therefore, calculations of orthotropic symmetrical laminates are actually the same as that for each ply, especially for laminates reinforced by bidirectional woven glass fabrics.

The thickness of a panel is far less than its length and width; therefore, the analysis of the panels could be assumed as plane stress problems: $\sigma_{3}=\tau_{23}=\tau_{31}=0$. The axes are shown in Figure 1, and the stress-strain relationships are shown in the matrix form as follows.

The axes directions and off-axis directions are as follows:

$$
\left\{\begin{array}{c}
\varepsilon_{1} \\
\varepsilon_{2} \\
\gamma_{12}
\end{array}\right\}=\left[\begin{array}{ccc}
S_{11} & S_{12} & 0 \\
S_{21} & S_{22} & 0 \\
0 & 0 & S_{66}
\end{array}\right]\left\{\begin{array}{c}
\sigma_{1} \\
\sigma_{2} \\
\tau_{12}
\end{array}\right\},
$$

where the flexibility matrix $\mathbf{S}$ can be expressed as

$$
\mathbf{S}=\left[\begin{array}{ccc}
S_{11} & S_{12} & 0 \\
S_{21} & S_{22} & 0 \\
0 & 0 & S_{66}
\end{array}\right]=\left[\begin{array}{ccc}
\frac{1}{E_{1}} & -\frac{v_{2}}{E_{2}} & 0 \\
-\frac{v_{1}}{E_{1}} & \frac{1}{E_{2}} & 0 \\
0 & 0 & \frac{1}{G_{12}}
\end{array}\right],
$$

where $E_{1}$ is the elastic modulus of 1-axis, $E_{2}$ is the elastic modulus of 2-axis, $v_{1}$ is the Poisson ratio of 1 -axis, $v_{2}$ is the Poisson ratio of 2-axis, and $G_{12}$ is the shear modulus in 1-2.

The off-axis stiffness is lower than that in the reinforcement direction, and the load may be transmitted along the off-axis direction for some irregular shell members. Therefore, the off-axis properties actually determine the lower limit of material properties.

In Figure 1, $x$ and $y$ are off-axes, and the off-axis stressstrain relationship can be obtained through the transformation formula. Thus, equation (2) can be transformed into the following equation:

$$
\begin{aligned}
\left\{\begin{array}{c}
\varepsilon_{x} \\
\varepsilon_{y} \\
\gamma_{x y}
\end{array}\right\}= & {\left[\begin{array}{ccc}
m^{2} & n^{2} & -m n \\
n^{2} & m^{2} & m n \\
2 m n & -2 m n & m^{2}-n^{2}
\end{array}\right]\left[\begin{array}{ccc}
S_{11} & S_{12} & 0 \\
S_{21} & S_{22} & 0 \\
0 & 0 & S_{66}
\end{array}\right] } \\
& \cdot\left[\begin{array}{ccc}
m^{2} & n^{2} & 2 m n \\
n^{2} & m^{2} & -2 m n \\
-m n & m n & m^{2}-n^{2}
\end{array}\right]\left\{\begin{array}{c}
\sigma_{x} \\
\sigma_{y} \\
\tau_{x y}
\end{array}\right\},
\end{aligned}
$$

where

$$
\begin{gathered}
m=\cos \theta, \\
n=\sin \theta .
\end{gathered}
$$

Therefore, the off-axis stiffness properties can be expressed as follows: 


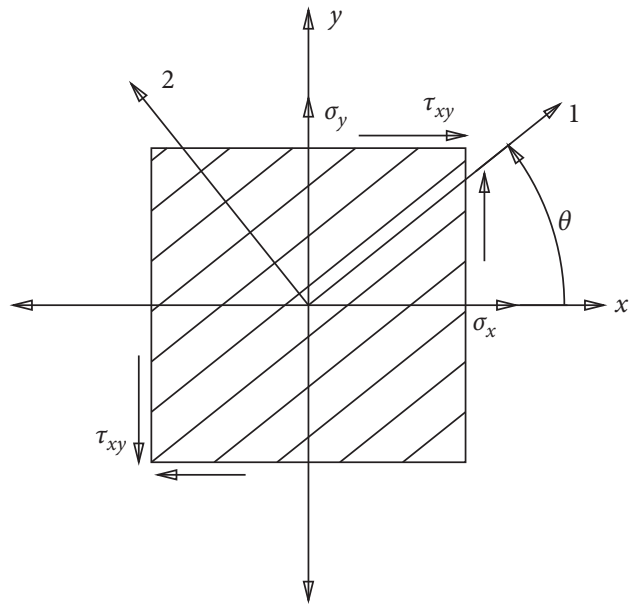

Figure 1: Material axis.

$$
\begin{aligned}
\frac{1}{E_{x}}= & \frac{1}{E_{1}} \cos ^{4} \theta+\left(\frac{1}{G_{12}}-\frac{2 v_{1}}{E_{1}}\right) \sin ^{2} \theta \cos ^{2} \theta+\frac{1}{E_{2}} \sin ^{4} \theta, \\
\frac{1}{E_{y}}= & \frac{1}{E_{1}} \sin ^{4} \theta+\left(\frac{1}{G_{12}}-\frac{2 v_{1}}{E_{1}}\right) \sin ^{2} \theta \cos ^{2} \theta+\frac{1}{E_{2}} \cos ^{4} \theta, \\
\frac{1}{G_{x y}}= & 2\left(\frac{2}{E_{1}}+\frac{2}{E_{2}}+\frac{4 v_{1}}{E_{1}}-\frac{1}{G_{12}}\right) \sin ^{2} \theta \\
& \cdot \cos ^{2} \theta+\frac{1}{G_{12}}\left(\sin ^{4} \theta+\cos ^{4} \theta\right), \\
v_{x}= & E_{x}\left[\frac{v_{1}}{E_{1}}\left(\sin ^{4} \theta+\cos ^{4} \theta\right)\right.
\end{aligned}
$$$$
\left.-\left(\frac{1}{E_{1}}+\frac{1}{E_{2}}-\frac{1}{G_{12}}\right) \sin ^{2} \theta \cos ^{2} \theta\right],
$$$$
v_{y}=E_{y}\left[\frac{v_{1}}{E_{1}}\left(\sin ^{4} \theta+\cos ^{4} \theta\right)\right.
$$$$
\left.-\left(\frac{1}{E_{1}}+\frac{1}{E_{2}}-\frac{1}{G_{12}}\right) \sin ^{2} \theta \cos ^{2} \theta\right],
$$

where $E_{x}$ is the elastic modulus of $x$-axis, $E_{y}$ is the elastic modulus of the $y$-axis, $v_{x}$ is the Poisson ratio of $x, v_{y}$ is the Poisson ratio of $y$, and $G_{x y}$ is the shear modulus in $x-y$.

For orthotropic symmetrical laminates, $E_{1}=E_{2}$. The derivation of $1 / E_{1}$ is shown in the following equation:

$$
\begin{aligned}
\frac{d\left(1 / E_{x}\right)}{d \theta}= & -\frac{4}{E_{1}} \sin \theta \cos ^{3} \theta+2 \sin \theta \cos \theta\left(\frac{1}{G_{12}}-\frac{2 v_{1}}{E_{1}}\right) \\
& \cdot\left(\cos ^{2} \theta-\sin ^{2} \theta\right)+\frac{4}{E_{1}} \sin ^{3} \theta \cos \theta \\
= & \left(\frac{1}{2 G_{12}}-\frac{v_{1}+1}{E_{1}}\right) \sin 4 \theta .
\end{aligned}
$$

Therefore, when

$$
\begin{aligned}
\theta & =\frac{n \pi}{4}, \quad n=0,1,2,3, \ldots, \\
\text { or } E_{1} & =2 G\left(v_{1}+1\right) .
\end{aligned}
$$

$E_{x}$ is at the extremum. Equation (9) corresponds to the isotropic material. For orthotropic symmetrical laminates, $E_{(\pi / 4)}$ is minimum and is given by $\left(4 E_{1} G_{12}\right) /\left(E_{1}+2 G_{12}\right.$ $\left.\left(1-v_{1}\right)\right)$. The simplification focuses on the elastic modulus as it is the main factor of panel deformation, and $E_{(\pi / 4)}$ may be taken as the elastic modulus of a simplified isotropic material.

The stiffness properties of orthotropic symmetrical GFRP laminates applied in the actual structure described in chapter 4 are shown in Table 1.

Substituting the properties in Table 1 into equation (6), and the off-axis property variation curves with $\theta$ are shown in Figures 2-4.

When $\theta=45^{\circ}, E_{(\pi / 4)}=9.074 \mathrm{GPa}$, which is minimum; $v_{(\pi / 4)}=0.512, G_{x y}=7.018 \mathrm{GPa}$, which are maximum. In contrast with isotropic materials, Poisson's ratio $v_{(\pi / 4)}=$ 0.512 , which is greater than 0.5 , is possible for anisotropic material, and it could be less than 0 as well.

3.2. Strength. Here, the Tsai-Hill criterion is applied as the failure criterion of GFRP laminate. The general form of the formula is given in following equation:

$$
\begin{aligned}
& F\left(\sigma_{2}-\sigma_{3}\right)^{2}+G\left(\sigma_{3}-\sigma_{1}\right)^{2}+H\left(\sigma_{1}-\sigma_{2}\right)^{2}+2 L \tau_{23}^{2} \\
& \quad+2 M \tau_{31}^{2}+2 N \tau_{12}^{2}=1 .
\end{aligned}
$$

In the case of plane stress problems, $\sigma_{3}=\tau_{23}=\tau_{31}=0$. For orthotropic symmetrical GFRP laminates, the fibers are distributed equally in the 1 and 2 directions and $X=Y$, where $X$ and $Y$ are the axis strengths in longitudinal and transverse directions, respectively. Therefore, the strength parameters $H, G, F$, and $N$ are confirmed and shown in the following equations: 
TABLE 1: Stiffness properties of 0 and $90^{\circ}$ orthotropic symmetrical GFRP laminates.

\begin{tabular}{lccc}
\hline$E_{1}$ & $E_{2}$ & $G_{12}$ & $v_{1}$ \\
\hline $16 \mathrm{GPa}$ & $16 \mathrm{GPa}$ & $3 \mathrm{GPa}$ & 0.14 \\
\hline
\end{tabular}

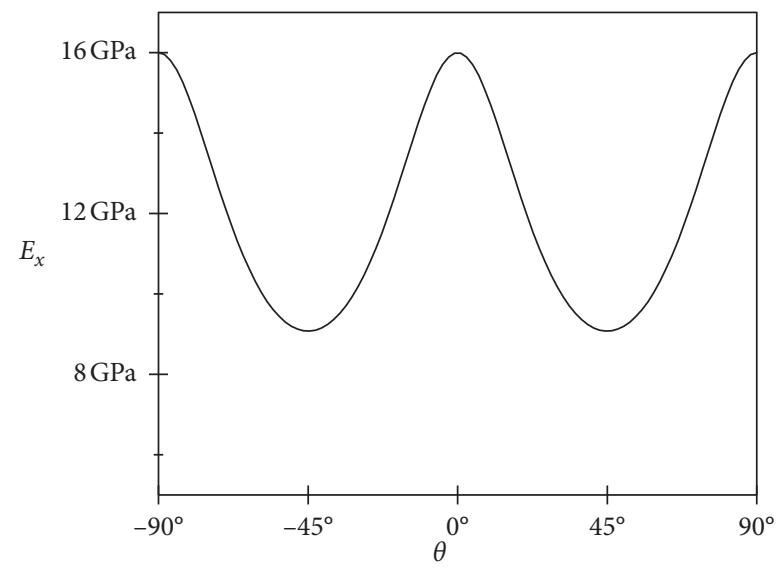

Figure 2: Off-axis elastic modulus variation curves with $\theta$.

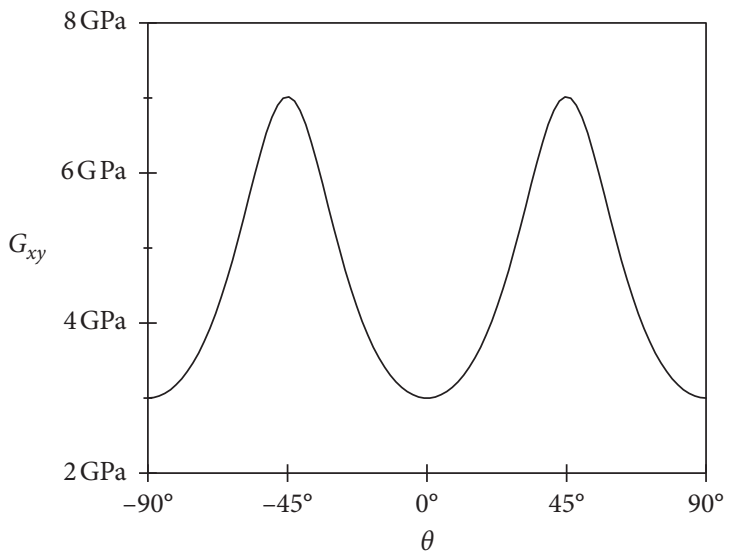

Figure 3: Off-axis shear modulus variation curves with $\theta$.

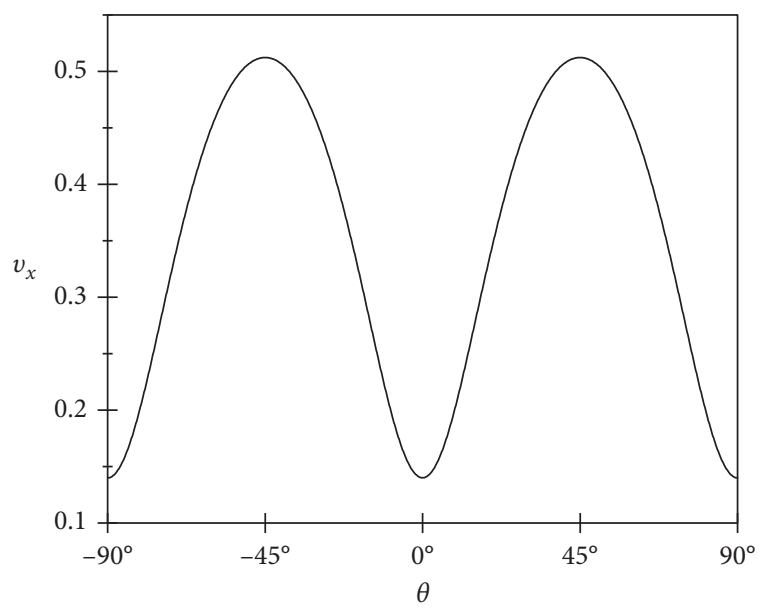

FIgURe 4: Off-axis Poisson's ratio variation curves with $\theta$.

$$
\begin{aligned}
& H=\frac{1}{2}\left(\frac{2}{X^{2}}-\frac{1}{Z^{2}}\right), \\
& G=\frac{1}{2 Z^{2}}, \\
& F=\frac{1}{2 Z^{2}}, \\
& N=\frac{1}{2 S^{2}},
\end{aligned}
$$

where $Z$ is the strength in thickness direction and $S$ is the shear strength in 1-2.

So, equation (10) can be expressed as equation (15) for orthotropic symmetrical laminates:

$$
\frac{\sigma_{1}^{2}}{X^{2}}+\frac{\sigma_{2}^{2}}{X^{2}}-\frac{2 \sigma_{1} \sigma_{2}}{X^{2}}+\frac{\sigma_{1} \sigma_{2}}{Z^{2}}+\frac{\tau_{12}^{2}}{S^{2}}=1
$$

When the laminates are subjected to unidirectional load, $\sigma_{1}, \sigma_{2}$, and $\tau_{12}$ can be transformed into $\sigma_{x}$ (stress in off-axis) as follows:

$$
\begin{aligned}
\sigma_{1} & =\sigma_{x} \cos ^{2} \theta, \\
\sigma_{2} & =\sigma_{x} \sin ^{2} \theta, \\
\tau_{12} & =-\sigma_{x} \sin \theta \cos \theta .
\end{aligned}
$$

Then, equation (15) can be converted into following equation:

$$
\frac{1}{\sigma_{x}^{2}}=\frac{\cos ^{2} 2 \theta}{X^{2}}+\frac{1}{4}\left(\frac{1}{Z^{2}}+\frac{1}{S^{2}}\right) \sin ^{2} 2 \theta .
$$

The derivation of $1 / \sigma_{x}^{2}$ is shown in the following equation:

$$
\begin{aligned}
\frac{d\left(1 / \sigma_{x}^{2}\right)}{d \theta} & =-\frac{4}{X^{2}} \cos 2 \theta \sin 2 \theta+\left(\frac{1}{Z^{2}}+\frac{1}{S^{2}}\right) \sin 2 \theta \cos 2 \theta \\
& =\sin 4 \theta\left(\frac{1}{2 Z^{2}}+\frac{1}{2 S^{2}}-\frac{2}{X^{2}}\right) .
\end{aligned}
$$

Therefore, $\sigma_{(\pi / 4)}$ is minimum: $2 S Z / \sqrt{S^{2}+Z^{2}}$, and this strength can be a reference parameter for simplified material strength.

Strength properties of orthotropic symmetrical GFRP laminates applied in the actual structure described in chapter 4 are shown in Table 2.

Substitute the properties of Table 2 into equation (17), and the off-axis strength variation curves with $\theta$ are shown in Figures 5 and 6.

Appropriate failure criteria and strength parameters must be selected for the simplified isotropic material. The maximum stress criterion assumes that a material fails when the maximum principal stress exceeds the uniaxial tensile strength, and it is commonly applied among brittle materials like concrete. GFRP is essentially a brittle material and therefore, the maximum stress criterion might be appropriate for the simplified isotropic material. The stress-strain curves of brittle materials in uniaxial load experiments are 
TABLE 2: Strength properties of 0 and $90^{\circ}$ orthotropic symmetrical GFRP laminates.

\begin{tabular}{lcccc}
\hline$X_{t}$ & $X_{c}$ & $Z_{t}$ & $Z_{c}$ & $S$ \\
\hline $300 \mathrm{MPa}$ & $250 \mathrm{MPa}$ & $60 \mathrm{MPa}$ & $120 \mathrm{MPa}$ & $70 \mathrm{MPa}$ \\
\hline
\end{tabular}

where $X_{t}$ is the tension strength of 1-axis (the same as 2-axis), $X_{c}$ is the compression strength of 1-axis, $Z_{t}$ is the tension strength in thickness direction, and $Z_{c}$ is the compression strength in thickness direction.

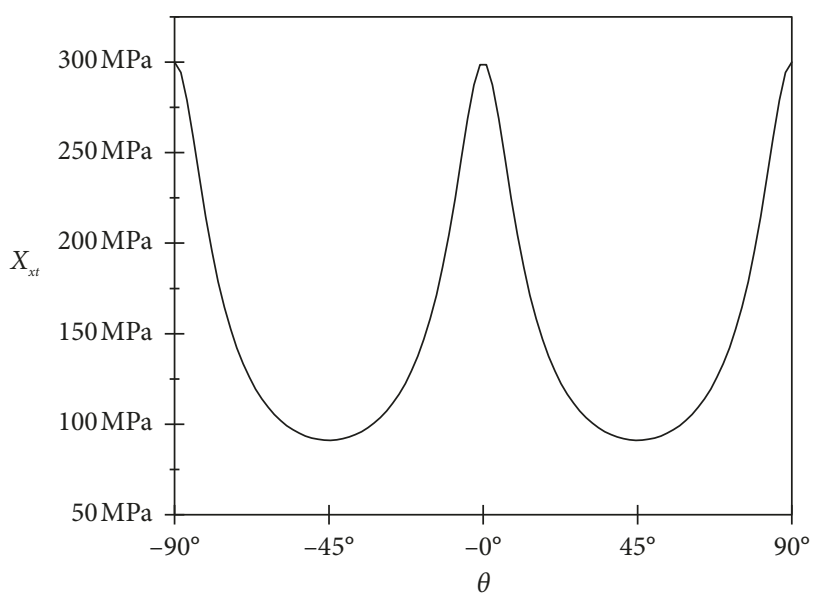

Figure 5: Off-axis tension strength variation curves with $\theta$.

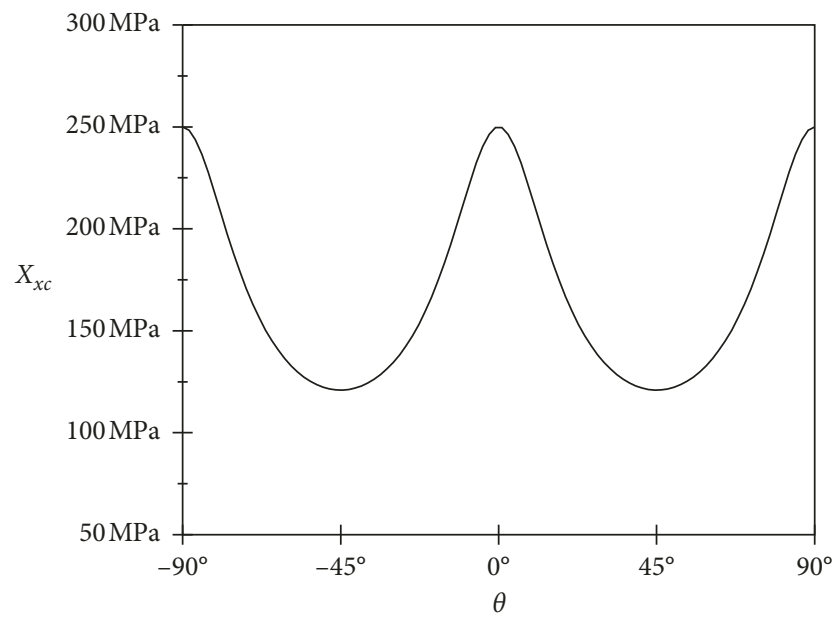

FIgURE 6: Off-axis compression strength variation curves with $\theta$.

always oblique lines terminated at the ultimate strain values, as shown in Figure 7(a), and the design strengths are commonly obtained by dividing the ultimate stresses by safety factors. Thus, many studies focus on the determination of this safety factor. However, another method to obtain the design strength of simplified isotropic material is proposed here.

Members like facade panels are subjected primarily to bending loads. Bending strength and bending modulus, which are obtained from bending tests, are common parameters for FRP. There are many factors that influence bending properties, including the type of polymer and fiber and the ply-stacking sequence. And thus, bending properties are a reflection of the overall material properties. A typical

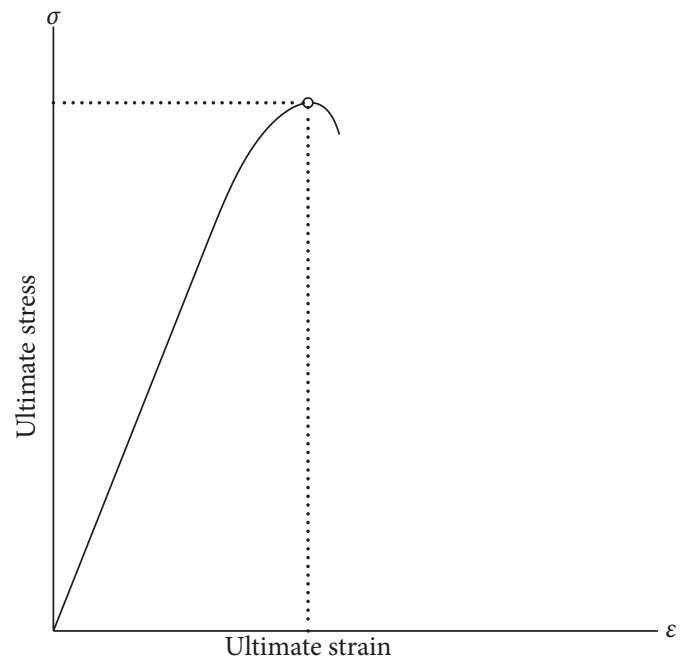

(a)

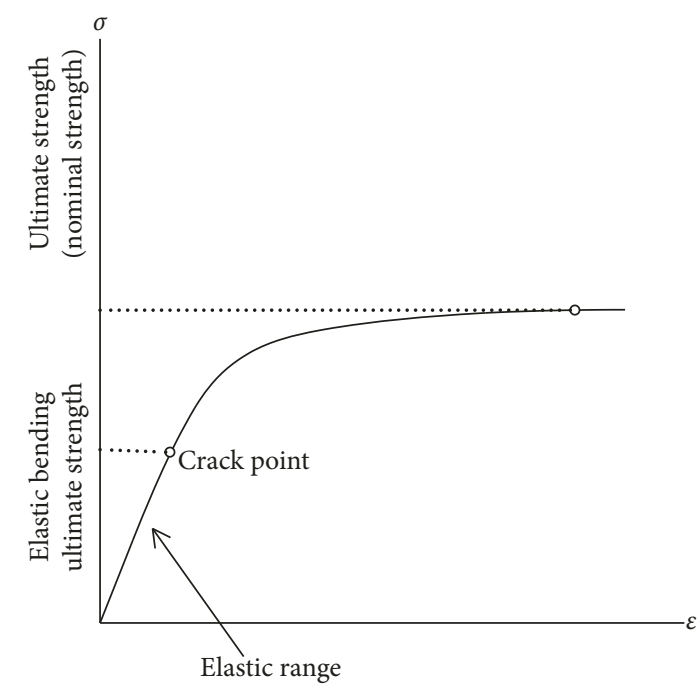

(b)

FIgURE 7: Stress-strain curves. (a) Brittle materials (including FRP) in uniaxial load experiment. (b) FRP in bending test.

stress-strain curve of FRP in bending test is shown in Figure 7(b), which is totally different from the curve of brittle materials in Figure 7(a) and is indeed possible especially for highly orthotropic laminates. There is a long horizontal section, and it seems to be a curve of a ductile material.

The formulas provided in bending test standards, such as ASTM D790 [29], to calculate the bending stress and strain in Figure 7(b) are based on homogeneous elastic material. Actually, they are not totally appropriate for highly orthotropic laminates. The specific explanation is very complicated and different for different FRP. However, bending properties are applied as parameters of the simplified solution in this paper, and therefore, only a brief explanation is listed below, which could be applied for common GFRP, including the GFRP applied in this paper.

Within the elastic range of the curve in Figure 7(b), bending stresses are equivalent to the compressive and tensile stresses on the surface of the specimen, and the same 
applies to bending modulus. The elastic bending properties can be computed theoretically through formulas, and the practical elastic bending ultimate strength can be obtained at the end of the elastic range.

The compression strength of polymers (the matrix of GFRP) is generally higher than its tensile strength, and so, in bending experiments, the polymers in tensile side cracks and fails first ("crack point" in Figure 7(b)). Though the glass fiber of the tensile side can still bear the load, the bending stress formula is invalid. Therefore, the curve after the crack point in Figure 7(b) is a nominal stress-strain curve and the bending ultimate strength is a nominal strength, which is often applied as a qualitative criterion.

The elastic bending ultimate strength (stress on the crack point of Figure 7(b)) of GFRP at $\pm 45^{\circ}$ is generally much less than its ultimate strength. But when applied as facade panels, stresses in the GFRP panel under a common load are much lower than the GFRP ultimate strengths and even lower than the elastic bending ultimate strength. The design of a GFRP panel is mainly controlled by deformation in general. Therefore, the elastic bending ultimate strength of GFRP at $\pm 45^{\circ}$ may be applied directly as the design strength of the maximum stress criterion for simplified isotropic material.

3.3. Simplified Material Solution. The aim of this study is to simplify and idealize orthotropic symmetrical GFRP laminates into isotropic material. Theoretically, the stiffness and strength of orthotropic symmetrical GFRP laminates are both minimum at $\pm 45^{\circ}$; therefore, it is safe to consider $\pm 45^{\circ}$ properties as the basic properties of the simplified isotropic material; GFRP is a brittle material, and thus, the maximum stress criterion is employed as the failure criterion. GFRP facade panels are mainly subjected to bending loads. Hence, through bending tests at $\pm 45^{\circ}$ of orthotropic symmetrical GFRP laminates, the bending modulus can be employed as the elastic modulus of simplified isotropic material and elastic bending ultimate strength can be employed as the failure strength. An isotropic material has only two independent parameters, which often adopt the elastic modulus and Poisson's ratio in engineering, so the shear modulus is not independent. Poisson's ratio has a relatively small effect on deformation and can be assumed as 0.3 for common orthotropic symmetrical GFRP laminates.

A brief solution is shown in Table 3.

\section{Overview of the Structure}

In 2017, a structure with a free-form facade was built in Fuzhou, China. The architectural schematic is a sculpturelike structure representing three morning glories: a considerably free-form facade with strong visual impact. The facade model is shown in Figure 8. To realize the architecture, orthotropic symmetrical GFRP laminates were finally applied as facade materials, which could reduce construction time as well as cost. The simplified material solution was applied to calculate facade panel parameters in the design phase, and the structure was completed in December 2017, as shown in Figure 9. The simplified material
TABLE 3: Simplified material solution.

\begin{tabular}{lcccc}
\hline $\begin{array}{l}\text { Material } \\
\text { properties }\end{array}$ & $\begin{array}{c}\text { Elastic } \\
\text { modulus }\end{array}$ & $\begin{array}{c}\text { Poisson's } \\
\text { ratio }\end{array}$ & $\begin{array}{c}\text { Failure } \\
\text { criterion }\end{array}$ & Failure strength \\
\hline $\begin{array}{l}\text { Isotropic } \\
\text { material }\end{array}$ & $\begin{array}{c} \pm 45^{\circ} \\
\text { bending } \\
\text { modulus }\end{array}$ & 0.3 & $\begin{array}{c}\text { The } \\
\text { maximum } \\
\text { stress } \\
\text { criterion }\end{array}$ & $\begin{array}{c} \pm 45^{\circ} \text { elastic } \\
\text { bending } \\
\text { ultimate } \\
\text { strength }\end{array}$ \\
\hline
\end{tabular}

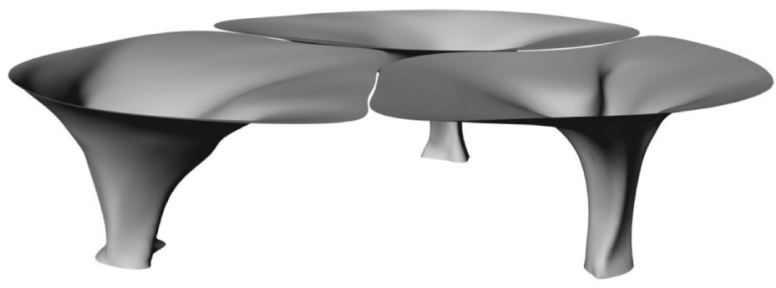

Figure 8: Facade model.

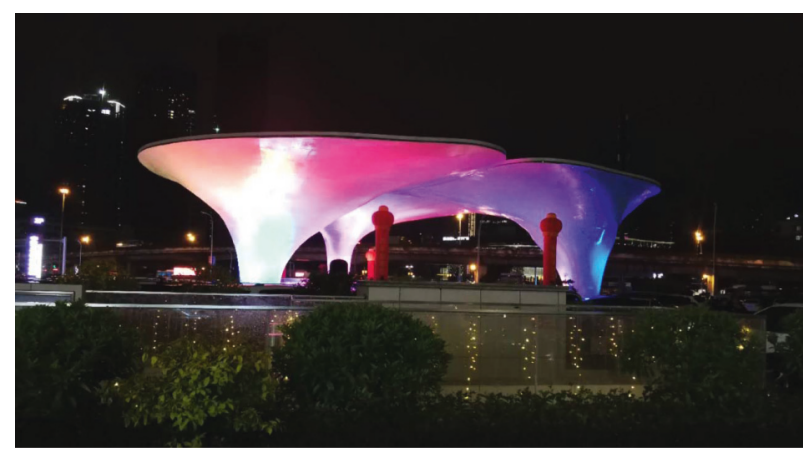

FIgURE 9: Night view.

solution will be evaluated by bending tests and numerical simulation of the actual structure.

The height of the structure is $9.8 \mathrm{~m}$, and the surface area is approximately $1460 \mathrm{~m}^{2}$. The structure is completely exposed to open air, covering the entire sunken plaza and protecting it from rain. The inner supporting structures are steel tubes and $T$-section purlins. As Fuzhou is located near the coast and affected by Pacific typhoons in summer, the basic wind load is relatively large, and the wind load must include both wind suction and pressure as an open structure. According to the Load Code for the Design of Building Structures [30], the basic wind pressure is $0.7 \mathrm{kN} / \mathrm{m}^{2}$ in Fuzhou. In the design phase of the structure, a load combination of $2.8 \mathrm{kN} / \mathrm{m}^{2}$ was applied to evaluate the deformation of members, and a load combination of $4 \mathrm{kN} / \mathrm{m}^{2}$ was applied to evaluate the strength. In the numerical simulation of chapter 6 in this paper, a load of $4 \mathrm{kN} / \mathrm{m}^{2}$ is applied on the panel to calculate the deformation and stresses.

\section{Bending Test}

5.1. Test Scope and Specimen. The bending properties of orthotropic symmetrical GFRP laminates applied in this structure are tested to obtain the bending modulus and elastic 
bending ultimate strength at $\pm 45^{\circ}$. The test procedure refers to ASTM D790: Standard Test Methods for Flexural Properties of Unreinforced and Reinforced Plastics and Electrical Insulating Materials [29]. Two batches of specimens were tested, and their material ingredients are shown in Table 4. The additive, ammonium polyphosphate, in Table 4 is a flame retardant, which is mixed in material $\mathrm{B}$. A limited amount of additive has no influence on the material properties since FRP properties are mainly determined by the fiber. The axis properties of the two batches are shown in Table 5 .

According to ASTM D790 [29], the specimen dimensions were prepared following Figure 10 and Table 6, and five specimens were prepared for each batch.

5.2. Test Result. The loading process and failed specimens are shown in Figures 11 and 12.

The tensile and compressive stresses and strain on specimen surfaces can be calculated using equations (19) and (20) within the elastic range:

$$
\begin{gathered}
\sigma_{f}=\frac{3 P s}{2 w d^{2}}, \\
\varepsilon_{f}=\frac{6 D d}{s^{2}},
\end{gathered}
$$

where $P$ is the load in the middle, $D$ is the deformation in the middle, $\sigma_{f}$ is the flexural stress, and $\varepsilon_{f}$ is the flexural strain.

After the tensile side cracks, equations (19) and (20) become invalid and the results calculated from them become nominal stresses and strains. The $\sigma_{f}-\varepsilon_{f}$ curves of the tests are shown in Figure 13.

The bending elastic modulus can be obtained from the test data when $\varepsilon_{f 1}=0.0005$ and $\varepsilon_{f 2}=0.0025$ by equation (21). The bending elastic moduli of specimens are shown in Table 7.

$$
E_{f}=\frac{\sigma_{f 2}-\sigma_{f 1}}{\varepsilon_{f 2}-\varepsilon_{f 1}} .
$$

The average elastic moduli are $9.86 \mathrm{GPa}$ and $9.71 \mathrm{GPa}$, respectively, which is close to $9.074 \mathrm{GPa}$ calculated theoretically but a little higher. The error is probably induced by two factors:

(a) $9.074 \mathrm{GPa}$ is calculated based on the properties in Table 1 . The properties in Tables 1 and 2 are provided by the GFRP manufacturer, and these properties are applied for design and calculation. Therefore, these properties might be conservative values and the real average values of these properties might be a little larger.

(b) The test error of $G_{12}$ is given in Table 1. The test methods for shear modulus of FRP are much more complicated compared with methods for tensile and compressive properties, and the principles of the test methods induce errors themselves. However, the value of $G_{12}$ indeed influences the value of $E_{(\pi / 4)}$ of orthotropic symmetrical GFRP laminates. The values of $E_{1}, E_{2}$, and $v_{1}$ are generally reliable. Therefore, assuming the values of $E_{1}, E_{2}$, and $v_{1}$ in Table 1 are
TABle 4: Material ingredients.

\begin{tabular}{lccccc}
\hline Batch & Fiber & $\begin{array}{c}\text { Fiber } \\
\text { volume } \\
\text { fraction } \\
(\%)\end{array}$ & Matrix & Additive & $\begin{array}{c}\text { Depth } \\
(\mathrm{mm})\end{array}$ \\
\hline $\begin{array}{l}\text { Material } \\
\text { A }\end{array}$ & $\begin{array}{c}\text { E- } \\
\text { Glass* }\end{array}$ & 50 & $\begin{array}{c}\text { Epoxy } \\
\text { resin }\end{array}$ & None & 5.7 \\
\hline $\begin{array}{l}\text { Material } \\
\text { B }\end{array}$ & $\begin{array}{c}\text { E- } \\
\text { Glass* }\end{array}$ & 50 & $\begin{array}{c}\text { Epoxy } \\
\text { resin }\end{array}$ & $\begin{array}{c}10 \% \\
\text { ammonium } \\
\text { polyphosphate }\end{array}$ & 4.8 \\
\hline
\end{tabular}

${ }^{*}$ E-Glass: alkali-free glass fiber.

TABle 5: Axis properties of the tested material.

\begin{tabular}{lcccc}
\hline Batch & $E_{1}\left(E_{2}\right)$ & $G_{12}$ & $v_{1}$ & $X_{t 1}\left(X_{t 2}\right)$ \\
\hline Material A/B & $16 \mathrm{GPa}$ & $3 \mathrm{GPa}$ & 0.14 & $300 \mathrm{MPa}$ \\
\hline
\end{tabular}

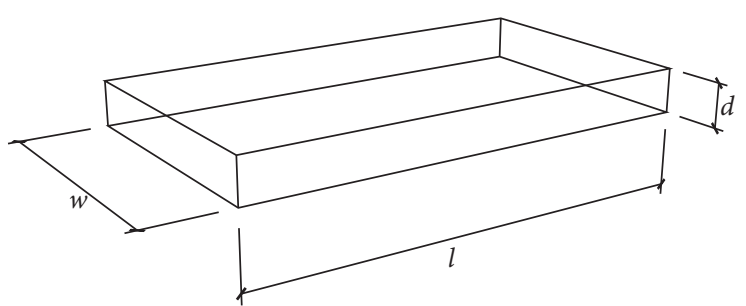

(a)

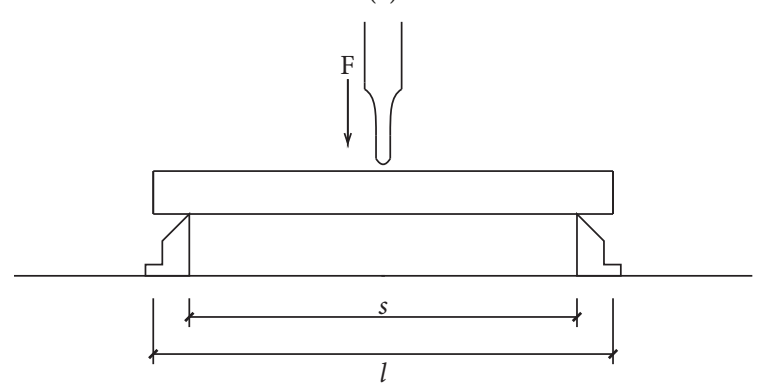

(b)

Figure 10: Specimens dimensions model. (a) 3D model. (b) Front view.

Table 6: Nominal specimen dimensions.

\begin{tabular}{lcccc}
\hline Batch & Length $(l)$ & Width $(w)$ & Depth $(d)$ & Span $(s)$ \\
\hline Material A & $110 \mathrm{~mm}$ & $12.7 \mathrm{~mm}$ & $5.7 \mathrm{~mm}$ & $91.2 \mathrm{~mm}$ \\
Material B & $92 \mathrm{~mm}$ & $12.7 \mathrm{~mm}$ & $4.8 \mathrm{~mm}$ & $76.8 \mathrm{~mm}$ \\
\hline
\end{tabular}

accurate, and according to equation (6) and the bending elastic moduli which were just obtained, 3.3 GPa might be a more proper value for $G_{12}$.

Yet, the little error does not influence the application of the simplified material solution.

In Figure 13, when the stresses are approximate $60 \mathrm{MPa}$, the tangent moduli of curves start to decline. Thus, $60 \mathrm{MPa}$ could be adopted as the ultimate elastic bending strength. At last, the stresses stop rising and the curves almost become horizontal. The nominal bending ultimate strengths in Figure 13 are approximate $120 \mathrm{MPa}$ and $140 \mathrm{MPa}$, respectively. 


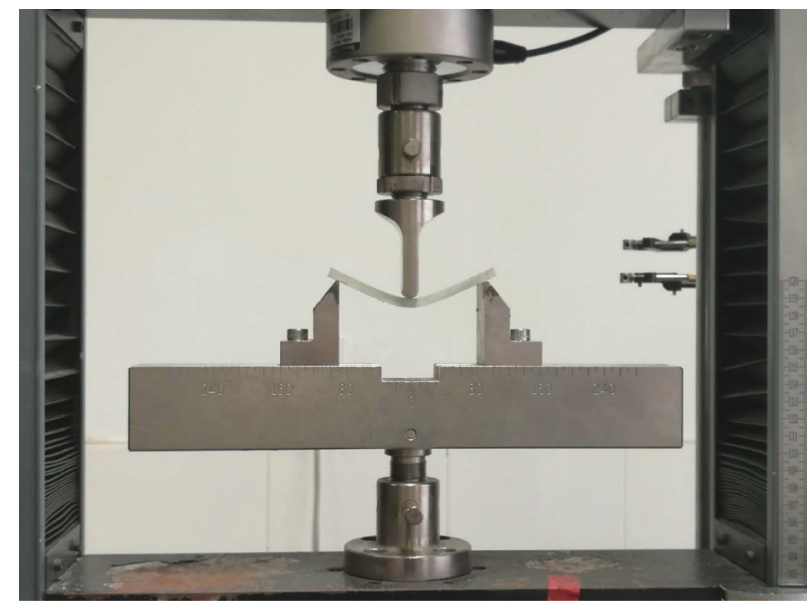

FIGURE 11: Three-point bending test.

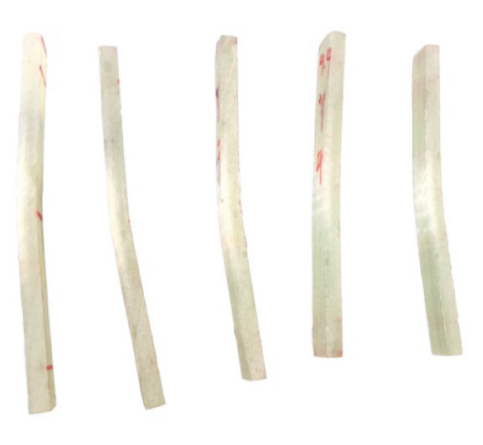

(a)

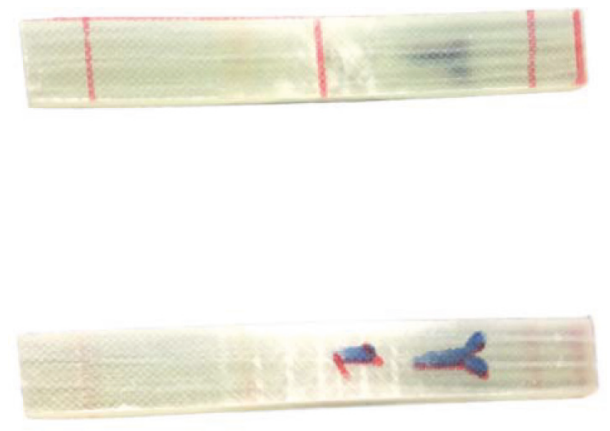

(b)

Figure 12: Failed specimens. (a) Side view. (b) Front view.

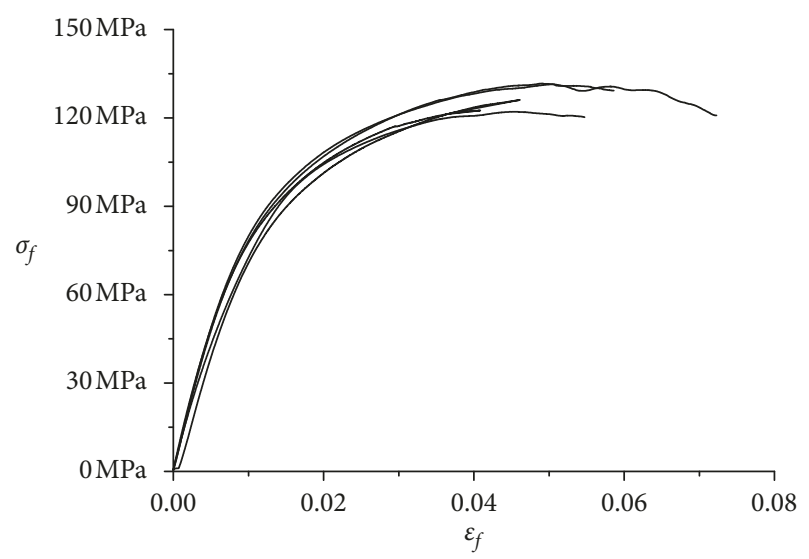

(a)

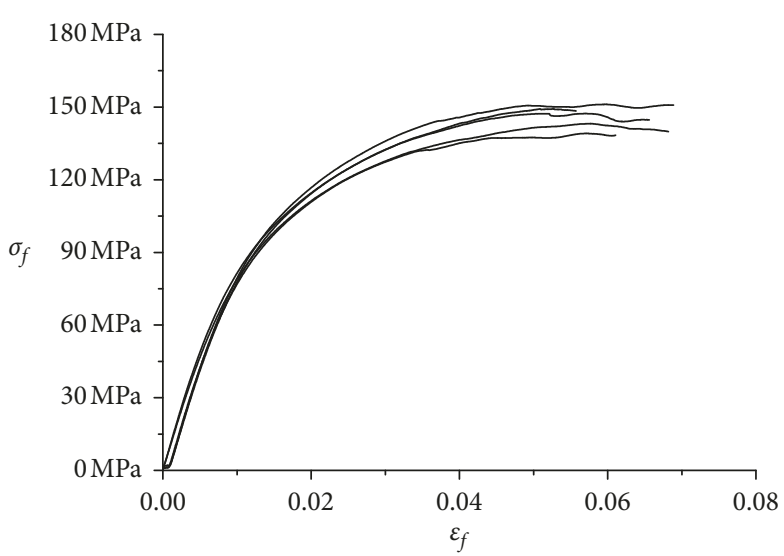

(b)

Figure 13: $\sigma_{f}-\varepsilon_{f}$ curves of bending tests. (a) Material A. (b) Material B.

TABLE 7: Bending elastic modulus.

\begin{tabular}{lcccccc}
\hline Specimens & 1 & 2 & 3 & 4 & 5 & Avg. \\
\hline Material A & $10.16 \mathrm{GPa}$ & $10.35 \mathrm{GPa}$ & $9.12 \mathrm{GPa}$ & $10.48 \mathrm{GPa}$ & $9.18 \mathrm{GPa}$ & $9.86 \mathrm{GPa}$ \\
Material B & $9.86 \mathrm{GPa}$ & $9.21 \mathrm{GPa}$ & $9.69 \mathrm{GPa}$ & $9.76 \mathrm{GPa}$ & $10.01 \mathrm{GPa}$ & $9.71 \mathrm{GPa}$ \\
\hline
\end{tabular}




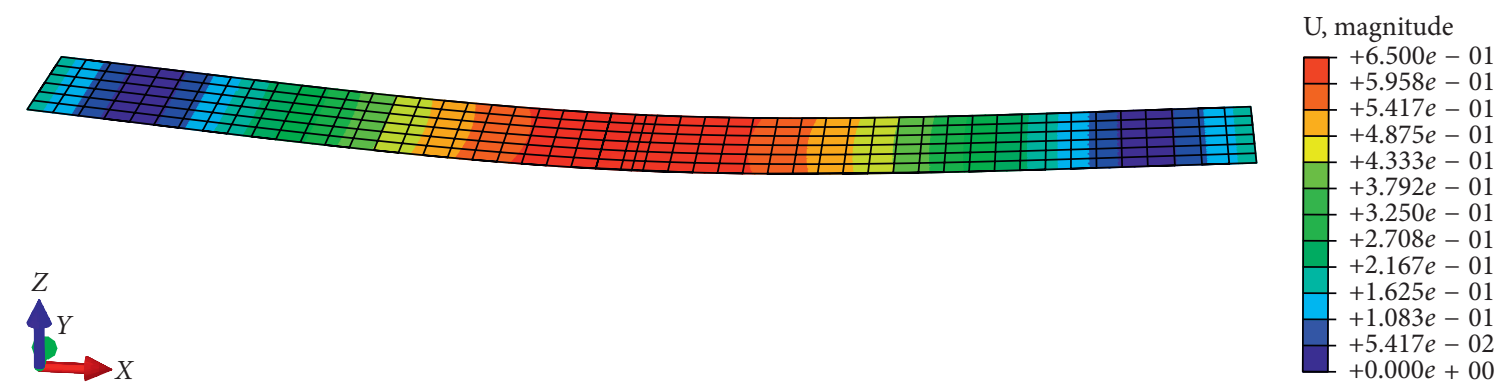

(a)
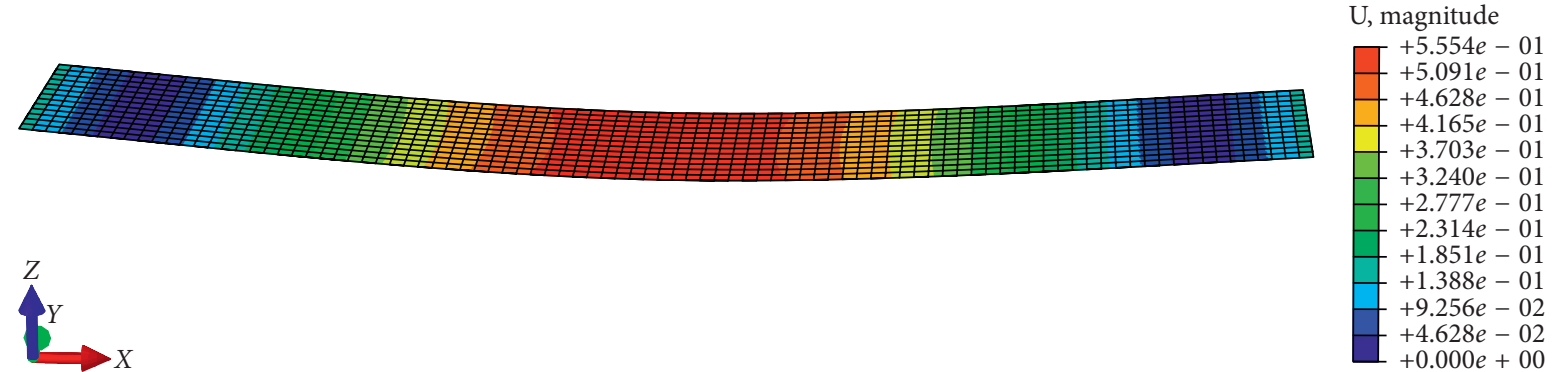

(b)

FIgURE 14: Deformation nephogram from the finite element method. (a) Material A. (b) Material B.

5.3. Numerical Simulation of the Bending Test. Numerical simulation of the bending test is conducted in Abaqus ${ }^{\mathrm{TM}}$. The multilayer and laminate material simulation functions of Abaqus $^{\mathrm{TM}}$ are relatively mature and widely used in the simulation of composite materials. The laminate material parameters and model dimensions used in Abaqus ${ }^{\mathrm{TM}}$ are listed in Tables 5 and 6, respectively; The reinforcement direction is $\pm 45^{\circ}$, and therefore, it is equivalent to test the $\pm 45^{\circ}$ bending properties of $0^{\circ}, 90^{\circ}$ reinforced laminates.

The loads at the center of the model are $74.35 \mathrm{~N}$ and $61.66 \mathrm{~N}$, respectively, and these are the forces when $\varepsilon_{f}=$ 0.0025 in the tests. The models are articulated at the same position as the bending tests. Geometric nonlinearity should be considered; however, as load and deformation are relatively small, it is not that important. The results of the calculation are shown in Figure 14.

The deformation at the center of materials $\mathrm{A}$ and $\mathrm{B}$ are $0.650 \mathrm{~mm}$ and $0.555 \mathrm{~mm}$, respectively. The bending modulus can be calculated through the following equation:

$$
E=\frac{P s^{3}}{4 w D d^{3}}
$$

The bending moduli of materials $\mathrm{A}$ and $\mathrm{B}$ at $\pm 45^{\circ}$, obtained from the numerical simulation, are $8.753 \mathrm{GPa}$ and $8.711 \mathrm{GPa}$, which are considerably close to the theoretical value of $9.074 \mathrm{GPa}$, and there is still a little error compared with $9.86 \mathrm{GPa}$ and $9.71 \mathrm{GPa}$ obtained from bending tests.

\section{Numerical Simulation of the Actual Structure}

6.1. Scope of the Simulation. The facade divisions and supporting purlins are shown in Figure 15. Every panel is a freeform panel that is different from each other. The maximum dimension of the panels is approximately $2 \mathrm{~m} \times 2 \mathrm{~m}$. Fifteen

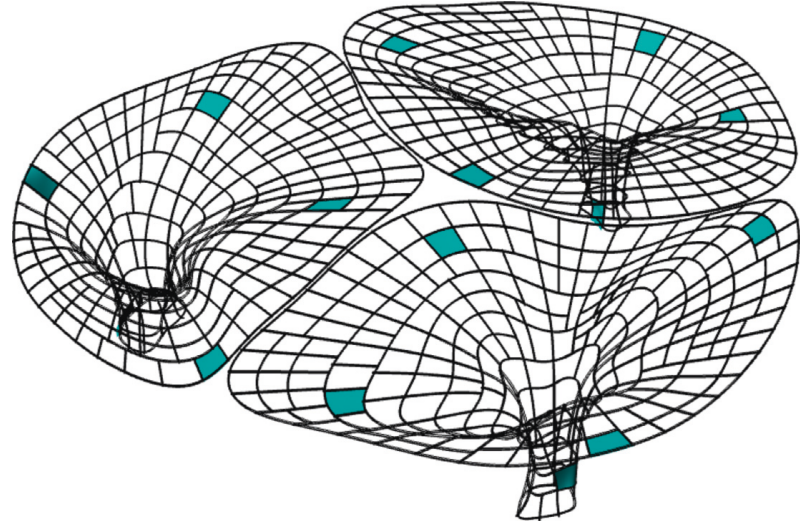

FIgURE 15: Facade division and supporting purlins.

panels, which are typical in position and shapes as shown in Figure 15, are selected for simulation in Abaqus ${ }^{\mathrm{TM}}$.

The fifteen selected panels include extremely twisted shapes as well as several flat ones. Simplified isotropic material properties and original orthotropic symmetrical GFRP laminate properties are given to the panels, respectively, following which the deformations and the stresses are calculated and the values of Tsai-Hill failure criterion of the laminate are evaluated. The specific analysis procedures are shown as follows.

Boundary conditions: panels are relatively thin and the elastic modulus is small; thus, the stiffness is small. Simultaneously, the panels are connected to purlins using structural adhesive. Therefore, the boundaries are assumed to be simply supported on all four sides.

Load: GFRP is light in weight and the panels are mainly subjected to wind loads. The wind load in Fuzhou is considerable, and the wind pressure and wind suction must be 
considered simultaneously. A load of $4 \mathrm{kN} / \mathrm{m}^{2}$ is applied in the numerical simulation after the combination.

Materials: this analysis focuses on the comparison of panels with different material properties, namely, the simplified isotropic material and original orthotropic symmetrical GFRP laminate. For GFRP laminate material, the panel depth of the structure is $4.8 \mathrm{~mm}, 0.6 \mathrm{~mm}$ for each layer and eight layers in total, and the material properties are the same as the material applied in the actual structure, as shown in Tables 1 and 2. The reinforcement directions of GFRP panels influence the deformation and stresses significantly. However, the shapes of free-form panels in Figure 15 are not regular. It is not realistic to control the reinforcement directions of every single panel during processing, especially for irregular shapes. Thus, the reinforcement directions of panels in the simulation are at the default setting of $0^{\circ}, 90^{\circ}$ in the local coordinates directly. For simplified isotropic material, the depth of the panel is also $4.8 \mathrm{~mm}$, while the elastic modulus varies as $9 \mathrm{GPa}, 10 \mathrm{GPa}, 11 \mathrm{GPa}, 12 \mathrm{GPa}, 13 \mathrm{GPa}$, $14 \mathrm{GPa}$, and $15 \mathrm{GPa}$, respectively, to evaluate errors, and Poisson's ratio is assumed to be 0.3 .

Analysis steps: the finite element method analysis must consider the geometric nonlinearity as the stiffness is typically low; the calculation includes the deformation and stresses of every mesh for all the isotropic materials and GFRP laminate material.

6.2. Numerical Simulation Result. The results of the deformations are listed in Table 8 and Figure 16. In Table 8, numbers in the first column are the panel number; values in the second column are the maximum deformations of every panel when adopting GFRP laminate property; values in the rest columns are the maximum deformations of every panel when adopting simplified isotropic materials with different elastic modulus.

The lines in Figure 16 are drawn by connecting the deformations in Table 8 to provide a more obvious contrast of the data. The bold line belongs to GFRP, and the others thin lines belong to simplified isotropic material with different elastic moduli.

The results of stresses in the panels are listed in Table 9. The numbers in the first column are the panel numbers. For simplified isotropic properties, since the influence of elastic modulus on the stresses is limited, only the largest absolute values of principal stresses in the panels when employing an elastic modulus of $13 \mathrm{GPa}$ are listed in the second column; and for the GFRP laminate property, the largest absolute values of positive-axis stresses and the maximum values of Tsai-Hill failure criterion are listed.

\subsection{Numerical Simulation Analysis}

6.3.1. Strength. In Table 9, the largest principal stress of the simplified isotropic panels is $26.53 \mathrm{MPa}$ and the largest positive-axis stress of the GFRP laminate panels is 21.78 MPa. The stresses are far smaller than the ultimate strength and even smaller than the elastic bending ultimate strength of the GFRP, which is $60 \mathrm{MPa}$. The value of Tsa-Hill failure criterion should be between 0 and 1 , where 1 means failure. The largest value of Tsai-Hill failure criterion in Table 9 is only 0.1764 . In general, strengths are not the key factors for GFRP facade panels, since the GFRP strengths are large enough.

6.3.2. Stiffness. In Table 8 and Figure 16, the deformation tendency of the simplified isotropic material panels is consistent with laminate panels. Assume the GFRP laminate deformations are the accurate values, and therefore, subtraction of GFRP laminate deformations and isotropic materials deformations can be considered as errors induced by material simplification. The errors norms are shown in Table 10.

The norms of $12 \mathrm{GPa}$ are the least in Table 10; therefore, simplified isotropic material with an elastic modulus of $12 \mathrm{GPa}$ is the material most similar to the GFRP laminate. However, the elastic modulus should be smaller than $12 \mathrm{GPa}$ for safety considerations. In Figure 16, the $9 \mathrm{GPa}$ curve is higher than the GFRP curve, and the $10 \mathrm{GPa}$ curve is almost higher than the GFRP curve but only a little lower at panel11. The theoretical elastic modulus of GFRP at $\pm 45^{\circ}$ is approximately $9 \mathrm{GPa}$, while the experimental value is approximately $10 \mathrm{GPa}$. Thus, it is reasonable to adopt the bending modulus of the orthotropic symmetrical GFRP laminate at $\pm 45^{\circ}$ as elastic modulus of simplified isotropic material.

In Table 8, the largest deformation is near $30 \mathrm{~mm}$. The Technical code for building curtain wall [31] stipulates that the maximum deformation should be no more than $1 / 60$ of the span. "1/60 of the span" is for glass, and it is the largest regulation. The regulation is different for different materials, and there is no regulation provided in the code for composite materials like GFRP. The spans of the panels are less than $2000 \mathrm{~mm}$, so that $30 \mathrm{~mm}$ is almost $1 / 60$. But the load applied in the numerical simulation is to evaluate the strength during the design phase of the structure. The load applied to evaluate deformation is smaller. And actually, the deformation ability of GFRP is much better than that of glass. Therefore, the stiffness of GFRP is enough considering function and safety problems.

6.4. Panel-Specific Analysis. In Table 8 and Figure 16, the deformation of panel- 8 is particularly presented. The deformation of GFRP laminate property is much less than the deformation of isotropic materials. The shape and reinforced direction of panel-8 are shown in Figure 17.

The reinforcement direction could not be completely perpendicular to the edges owing to its free-form shape. Rotating the reinforcement direction of panel-8 and recalculating its deformations, the largest deformation rises to $21.2 \mathrm{~mm}$ after a $20^{\circ}$ anticlockwise rotation of the reinforcement direction. This phenomenon indicates the customizability of GFRP properties. Under certain conditions, it is a mathematical extremum problem to obtain the most appropriate material properties and the best performance of the composite material. Considering panel-8, its minimum deformation can be obtained through rotation of orthotropic reinforcement 
TABLE 8: Maximum deformation of individual panels adopting different material properties (mm).

\begin{tabular}{lccccccc}
\hline \multirow{2}{*}{ Panel } & GFRP & \multicolumn{5}{c}{ Elastic modulus of simplified isotropic material } \\
& & $9 \mathrm{GPa}$ & $10 \mathrm{GPa}$ & $11 \mathrm{GPa}$ & $12 \mathrm{GPa}$ & $13 \mathrm{GPa}$ & $14 \mathrm{GPa}$ \\
\hline 1 & 2.92 & 2.99 & 2.72 & 2.50 & 2.31 & 2.14 & 2.00 \\
2 & 3.36 & 4.06 & 3.71 & 3.42 & 3.17 & 2.95 & 2.75 \\
3 & 4.40 & 7.84 & 6.03 & 4.38 & 3.18 & 2.45 & 1.98 \\
4 & 6.89 & 8.20 & 7.58 & 7.06 & 6.61 & 6.22 & 5.88 \\
5 & 9.81 & 10.71 & 10.05 & 9.46 & 8.95 & 8.49 & 8.06 \\
6 & 14.17 & 17.20 & 16.38 & 15.64 & 14.99 & 14.40 & 13.86 \\
7 & 17.13 & 20.11 & 19.07 & 18.17 & 17.18 & 16.67 & 16.02 \\
8 & 18.11 & 27.15 & 26.26 & 25.47 & 24.82 & 24.25 & 23.72 \\
9 & 19.66 & 21.13 & 20.23 & 19.43 & 18.71 & 18.06 & 13.36 \\
10 & 20.28 & 22.71 & 22.06 & 21.50 & 20.99 & 20.54 & 23.44 \\
11 & 20.79 & 21.41 & 20.40 & 19.49 & 18.64 & 17.83 & 20.13 \\
12 & 24.53 & 29.10 & 27.94 & 26.89 & 25.92 & 25.05 & 17.05 \\
13 & 25.21 & 27.40 & 26.55 & 25.81 & 25.15 & 24.56 & 24.25 \\
14 & 28.49 & 32.39 & 31.41 & 30.55 & 29.76 & 29.06 & 24.03 \\
15 & 29.50 & 30.85 & 30.15 & 29.49 & 28.89 & 28.32 & 28.41 \\
\hline
\end{tabular}

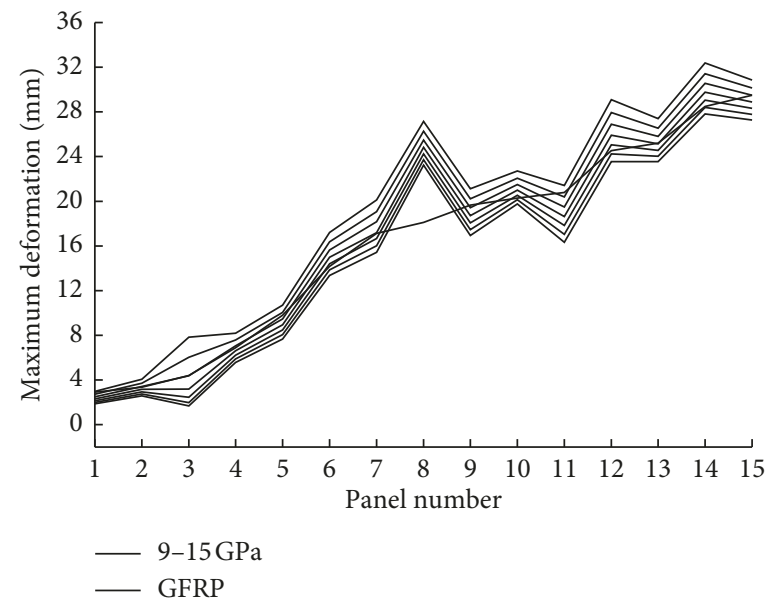

FIGURE 16: Maximum deformation curve of all panels (mm).

TABle 9: Maximum stresses of panels (MPa)

\begin{tabular}{|c|c|c|c|c|c|}
\hline \multirow[t]{2}{*}{ Panel } & \multirow{2}{*}{$\begin{array}{l}\text { Simplified isotropic } \\
\text { material } \\
\text { Elastic modulus: } 13 \mathrm{GPa}\end{array}$} & \multicolumn{3}{|c|}{$\begin{array}{c}\text { Positive-axis stresses } \\
\text { of GFRP }\end{array}$} & \multirow{2}{*}{$\begin{array}{c}\text { Values of Tsai-Hill } \\
\text { failure } \\
\text { criterion of GFRP }\end{array}$} \\
\hline & & $S 11$ & $S 22$ & $S 12$ & \\
\hline 1 & 4.682 & 4.912 & 4.487 & 2.338 & 0.03459 \\
\hline 2 & 8.993 & 9.484 & 7.852 & 2.379 & 0.03867 \\
\hline 3 & 4.492 & 10.140 & 8.888 & 5.862 & 0.07233 \\
\hline 4 & 7.695 & 9.560 & 10.020 & 3.100 & 0.05641 \\
\hline 5 & 10.720 & 9.363 & 9.252 & 4.653 & 0.06730 \\
\hline 6 & 14.360 & 17.280 & 16.690 & 4.554 & 0.08550 \\
\hline 7 & 12.190 & 11.160 & 11.450 & 2.830 & 0.05136 \\
\hline 8 & 26.530 & 19.350 & 17.110 & 8.140 & 0.11800 \\
\hline 9 & 15.760 & 20.670 & 18.210 & 3.950 & 0.08183 \\
\hline 10 & 17.270 & 21.780 & 17.540 & 4.013 & 0.08062 \\
\hline 11 & 17.620 & 17.370 & 20.140 & 8.410 & 0.08820 \\
\hline 12 & 15.770 & 13.750 & 14.540 & 5.510 & 0.07939 \\
\hline 13 & 14.770 & 11.940 & 14.380 & 3.630 & 0.06390 \\
\hline 14 & 16.850 & 16.010 & 15.450 & 4.890 & 0.07846 \\
\hline 15 & 22.790 & 20.240 & 21.530 & 13.070 & 0.17645 \\
\hline
\end{tabular}

where $S 11$ is the stress in 1-axis, $S 22$ is the stress in 2-axis, and $S 12$ is the shear stress in 1-2. 
TABLE 10: Norms of errors induced by material simplification.

\begin{tabular}{lccccccc}
\hline Norm & $9 \mathrm{GPa}$ & $10 \mathrm{GPa}$ & $11 \mathrm{GPa}$ & $12 \mathrm{GPa}$ & $13 \mathrm{GPa}$ & $14 \mathrm{GPa}$ & $15 \mathrm{GPa}$ \\
\hline 1 -norm & 37.996 & 26.471 & 18.675 & 17.891 & 19.714 & 23.084 & 28.915 \\
2 -norm & 12.876 & 10.219 & 8.435 & 7.640 & 7.653 & 8.198 & 9.057 \\
\hline
\end{tabular}

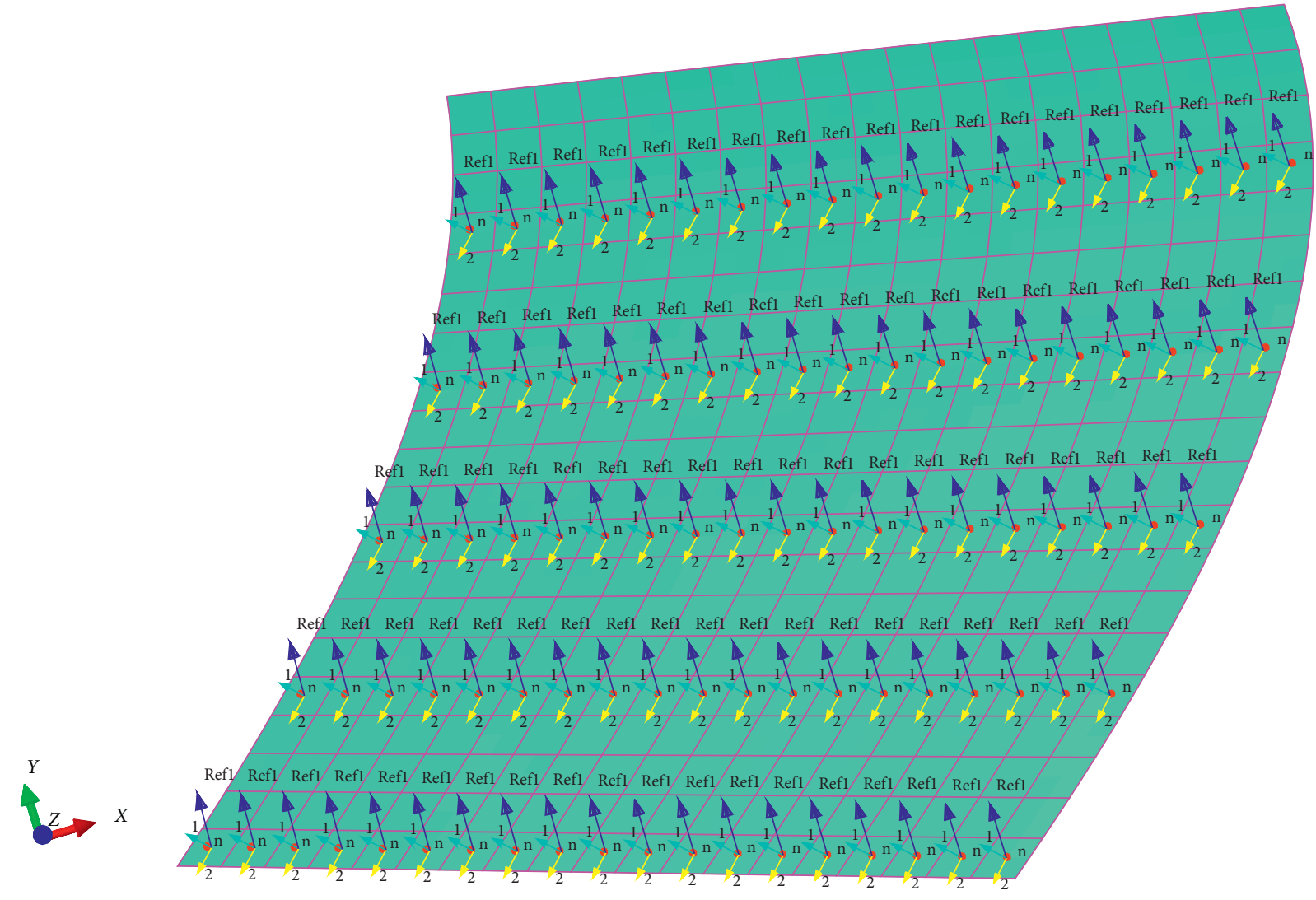

FIGURE 17: Shape and reinforced direction of panel-8.

direction or by abandoning orthotropic properties and rearranging the reinforcement directions.

\section{Discussion and Conclusion}

This paper proposed a simplified material solution for orthotropic symmetrical GFRP laminates used in structural facades. Reducing the difficulty of design as well as computational complexity can help promote the application of GFRP in civil engineering. Theoretically, the elastic modulus and strength in $\pm 45^{\circ}$ of the orthotropic symmetrical GFRP laminates are the smallest and can be applied as simplified material indexes. The elastic modulus and strength of the simplified material could take on the value of the bending elastic modulus and elastic bending ultimate strength that is obtained directly through the bending test of GFRP laminates in $\pm 45^{\circ}$. It is also proposed that the maximum stress criterion can be applied as the failure criterion of the simplified material model, and Poisson's ratio can take the value of 0.3 .

This simplified material solution is convenient to use and recommended for similar structures as reference. The following conclusions can be obtained through this study:
(1) The computational complexity and quantity of laminates are relatively large. The stiffness matrix of anisotropic laminates is highly complex, with an 8layer panel necessitating at least eight times the computational requirement. Coordination conditions between the layers further complicate the calculation, especially for free-form panels considering the recalculation and verification induced by design adjustments. In general, the analysis of integral structures by considering laminate material properties is very difficult, and the accuracy of the result might be doubtful. Even for single panels in this paper, multiple adjustments to element meshing and load steps have to be made to obtain reliable calculation results for some complicated panels when applying GFRP laminate properties. It is almost impossible to calculate GFRP facade structures by applying its original properties; thus, the simplified material solution obtained here becomes significant in promoting GFRP applications.

(2) GFRP panels are stiffness-controlled, and the strength is large enough. The applied value of $4 \mathrm{kN} / \mathrm{m}^{2}$ is a 
relatively large load combination. However, the largest value of Tsai-Hill failure criterion is only 0.1764 , while the largest principal tensile stress of simplified isotropic material is only $26.53 \mathrm{MPa}$, which is far smaller than the $\pm 45^{\circ}$ elastic bending ultimate strength, $60 \mathrm{MPa}$. The deformation is relatively large owing to the small stiffness of the GFRP. Therefore, the main design factor for the GFRP panels is deformation. In the Chinese code Technical code for building curtain wall, the regulation of glass facade, 1/60 of the span, is the largest deformation regulation, while the deformation ability of GFRP is much better than that of glass. Hence, it is suggested that the deformation regulation of GFRP could be larger than 1/60.

(3) The simplified material solution is effective. Deformation of the simplified isotropic material is consistent with that of GFRP laminate material properties and slightly higher considering the safety. Although the $\pm 45^{\circ}$ elastic bending ultimate strength of $60 \mathrm{MPa}$ seems to be much smaller than the ultimate strength of the GFRP, it is still sufficient for facade panels as design strength, even for extreme environmental conditions.

\section{Data Availability}

The experimental data used to support the findings of this study are included within the article.

\section{Conflicts of Interest}

The authors declare that there are no conflicts of interest regarding the publication of this paper.

\section{Acknowledgments}

This research was supported by the National Natural Science Foundation of China (Grant no. 51578404).

\section{References}

[1] C. E. Kurt, "Concrete filled structural plastic columns," Journal of the Structural Division, vol. 104, no. 1, pp. 55-63, 1978.

[2] C. E. Bakis, L. C. Bank, V. L. Brown et al., "Fiber-reinforced polymer composites for construction-state-of-the-art review," Journal of Composites for Construction, vol. 6, no. 2, pp. 73-87, 2002.

[3] H. T. Nguyen, H. Masuya, T. M. Ha et al., "Long-term application of carbon fiber composite cable tendon in the prestressed concrete bridge-shinmiya bridge in Japan," MATEC Web of Conferences, vol. 206, 2018.

[4] T. Yamashita, T. Kiuchi, H. Inukai et al., "PC bridge with new material-construction of Shinmiya Bridge," Prestressed Concrete, vol. 31, no. 2, pp. 71-78, 1989.

[5] B. Täljsten, "Strengthening concrete beams for shear with CFRP sheets," Construction and Building Materials, vol. 17, no. 1, pp. 15-26, 2003.

[6] H. J. Zadeh and A. Nanni, "Design of RC columns using glass FRP reinforcement," Journal of Composites for Construction, vol. 17, no. 3, pp. 294-304, 2012.
[7] H. J. Zadeh and A. Nanni, "Reliability analysis of concrete beams internally reinforced with fiber-reinforced polymer bars," Structural Journal, vol. 110, no. 6, pp. 1023-1032, 2013.

[8] G. B. Jumaa and A. R. Yousif, "Predicting shear capacity of FRP-reinforced concrete beams without stirrups by artificial neural networks, gene expression programming, and regression analysis," Advances in Civil Engineering, vol. 2018, Article ID 5157824, 16 pages, 2018.

[9] G. D. Tang, Y. Tang, and G. Z. Feng, "GRP bridges in China: research and practice," Journal of Chengdu University of Science and Technology, vol. 6, pp. 69-80, 1995.

[10] P. J. D. Mendes, J. A. O. Barros, J. M. Sena-Cruz, and M. Taheri, "Development of a pedestrian bridge with GFRP profiles and fiber reinforced self-compacting concrete deck," Composite Structures, vol. 93, no. 11, pp. 2969-2982, 2011.

[11] L. C. Hollaway, "A review of the present and future utilisation of FRP composites in the civil infrastructure with reference to their important in-service properties," Construction and Building Materials, vol. 24, no. 12, pp. 2419-2445, 2010.

[12] A. Saber and A. R. Ashok, "Behavior of FRP link slabs in jointless bridge decks," Advances in Civil Engineering, vol. 2012, Article ID 452987, 9 pages, 2012.

[13] A. Quarmby, The Plastics Architect, Pall Mall Press, London, UK, 1974.

[14] J. L. Meikle, American Plastic: A Cultural History, Rutgers University Press, New Brunswick, NJ, USA, 1995.

[15] M. Taanila, Futuro-Tomorrow's House from Yesterday, Desura, Helsinki, Finland, 2004.

[16] D. Kendall, "The business case for composites in construction," Reinforced Plastics, vol. 52, no. 7, pp. 20-27, 2008.

[17] M. Ju, H. Oh, and J. W. Sun, "Simplified reliability estimation for optimum strengthening ratio of 30-year-old double T-beam railway bridge by NSM techniques," Mathematical Problems in Engineering, vol. 2014, Article ID 734016, 10 pages, 2014.

[18] A. F. Pour, T. Ozbakkaloglu, and T. Vincent, "Simplified design-oriented axial stress-strain model for FRP-confined normal- and high-strength concrete," Engineering Structures, vol. 175, pp. 501-516, 2018.

[19] T. Ozbakkaloglu and J. C. Lim, “Axial compressive behavior of FRP-confined concrete: experimental test database and a new design-oriented model," Composites Part B: Engineering, vol. 55, pp. 607-634, 2013.

[20] A. F. Pour, A. Gholampour, J. Zheng, and T. Ozbakkaloglu, "Behavior of FRP-confined high-strength concrete under eccentric compression: tests on concrete-filled FRP tube columns," Composite Structures, vol. 220, pp. 261-272, 2019.

[21] D. Zhang, F. Li, F. Shao, and C. Fan, "Evaluation of equivalent bending stiffness by simplified theoretical solution for an FRP-aluminum deck-truss structure," KSCE Journal of Civil Engineering, vol. 23, no. 1, pp. 367-375, 2019.

[22] A. Machida and T. Uomoto, Recommendation for Design and Construction of Concrete Structures Using Continuous Fiber Reinforcing Materials, Japan Society of Civil Engineers, Tokyo, Japan, 1997.

[23] A. H. Zureick, B. R. Ellingwood, A. S. Nowak et al., Recommended Guide Specification for the Design of Externally Bonded FRP Systems for Repair and Strengthening of Concrete Bridge Elements, Transportation Research Board, Washington, D.C., USA, 2010.

[24] L. Ascione, J. F. Caron, P. Godonou et al., Prospect for New Guidance in the Design of FRP Support to the Implementation, Harmonization and Further Development of the Eurocodes, European Commission, Brussels, Belgium, 2016. 
[25] China Metallurgical Construction Association, Technical Code for Infrastructure Application of FRP Composites, China Planning Press, Beijing, China, 2011.

[26] Sichuan Department of Housing and Urban-Rural Development, Code for Design of Strengthening Concrete Structure, China Architecture \& Building Press, Beijing, China, 2014.

[27] R. Hill, The Mathematical Theory of Plasticity, Oxford University Press, England, UK, 1998.

[28] S. W. Tsai and E. M. Wu, "A general theory of strength for anisotropic materials," Journal of Composite Materials, vol. 5, no. 1, pp. 58-80, 1971.

[29] ASTM, D790-10: Standard Test Methods for Flexural Properties of Unreinforced and Reinforced Plastics and Electrical Insulating Materials, American Society for Testing Materials, West Conshohocken, PA, USA, 2010.

[30] Ministry of Housing and Urban-Rural Development of the People's Republic of China, Load Code for the Design of Building Structures, China Architecture \& Building Press, Beijing, China, 2012.

[31] Shanghai Metal Construction Association, DGJ08-56-2012: Technical Code for Building Curtain Wall, Shanghai Metal Construction Association, Shanghai, China, 2012. 


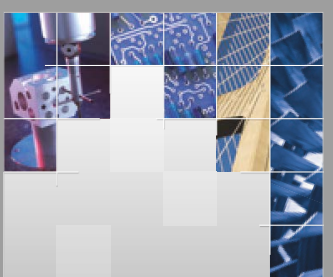

\section{Enfincering}
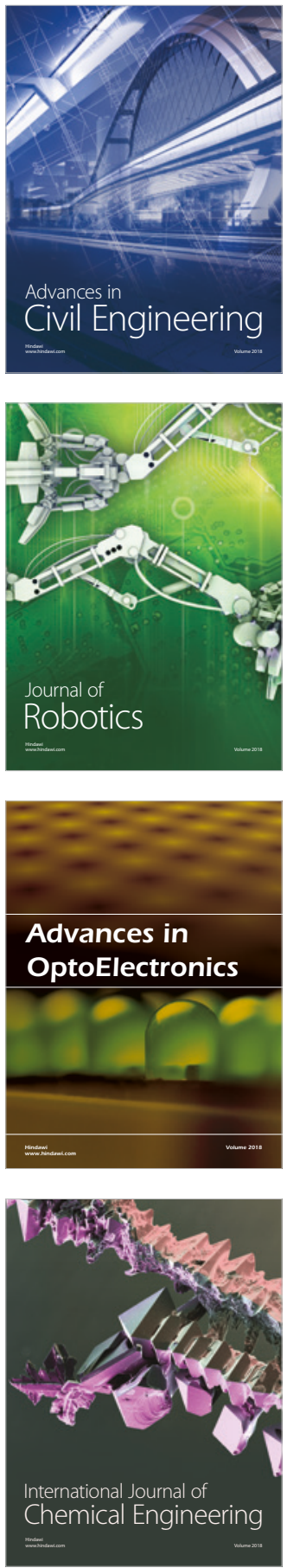

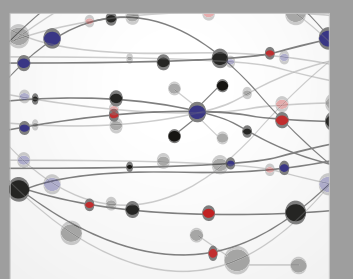

\section{Rotating \\ Machinery}

The Scientific World Journal

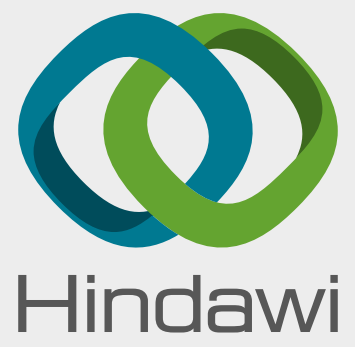

Submit your manuscripts at

www.hindawi.com
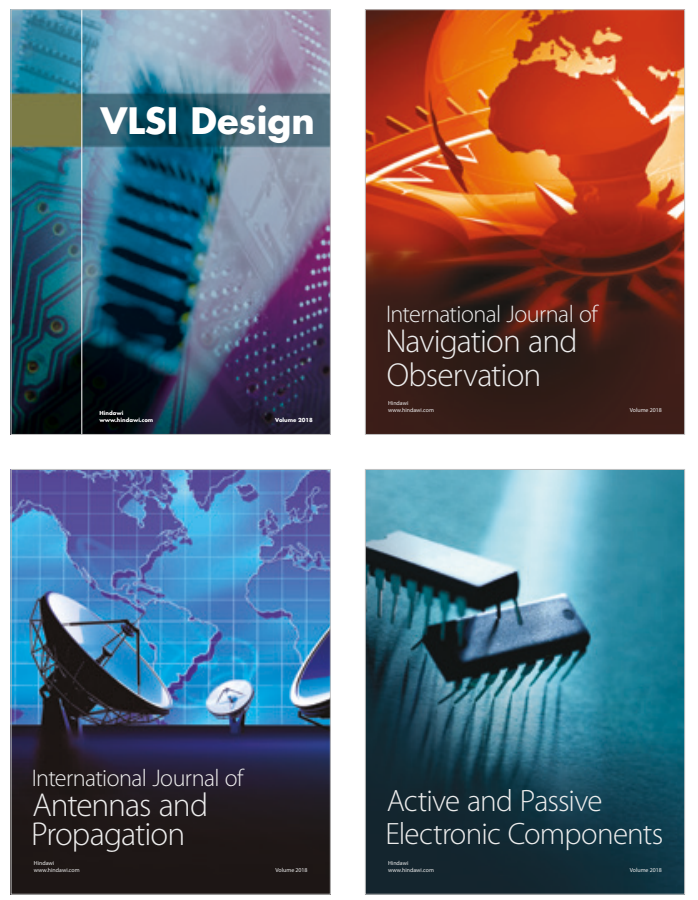
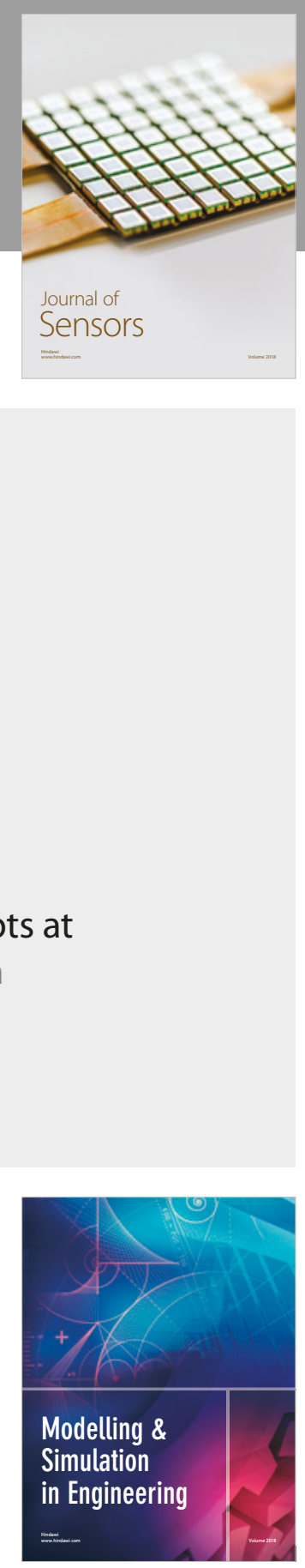

\section{Advances \\ Multimedia}
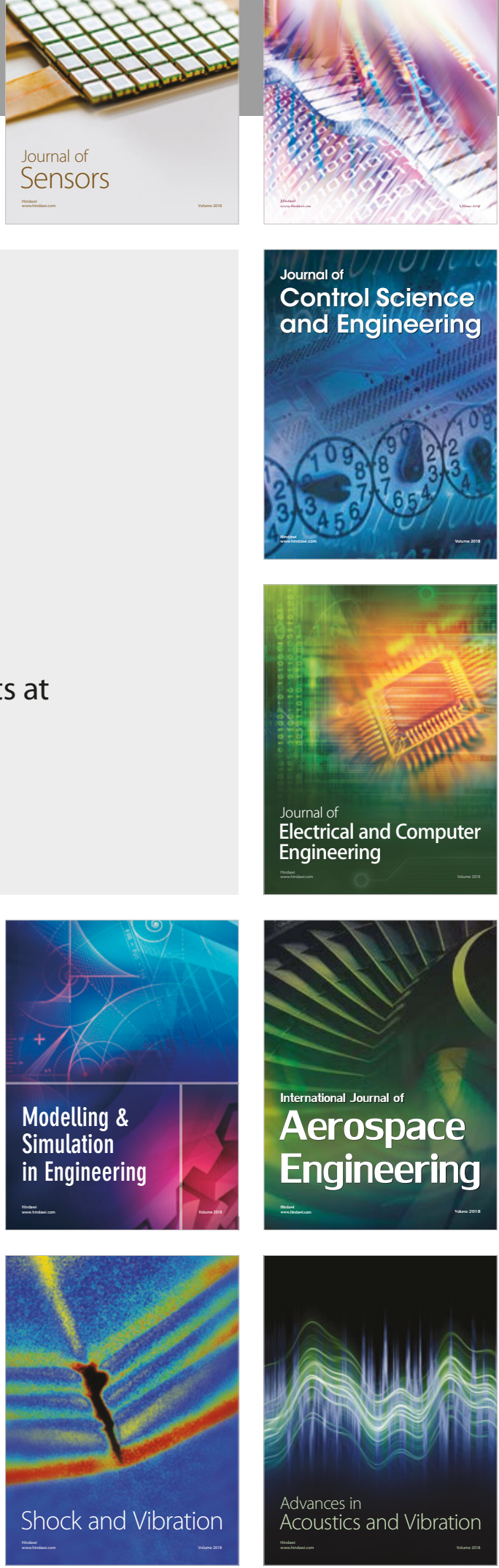